\title{
EDUCAÇÃO EMPREENDEDORA E CAMPANHA DE PUBLICIDADE ONLINE (ESTUDO DE CASO DE FRANQUIAS DA NATURA)
}

\author{
Henrique Rodrigues Muller ${ }^{1}$
}

\section{RESUMO}

Apresenta-se, neste escrito, uma breve fala sobre a importância da educação empreendedora para então, aprofundarmos o tema foco deste artigo que é a campanha publicitária online. Para tanto, será analisado um caso real, envolvendo as franquias da Natura, indústria brasileira de cosméticos. Desse modo, será elaborado um planejamento e uma campanha de publicidade online para uma franquia da Natura (loja física), visando ampliar suas vendas, sem entrar em conflitos éticos e profissionais de concorrência com a própria franqueadora.

Palavras-Chave: Educação empreendedora. Campanha de Publicidade. Publicidade On-line; Franquias. Ética Profissional.

\begin{abstract}
This writing presents a brief talk about the importance of entrepreneurial education so that we can deepen the focus of this writing, which is the online advertising campaign. For that, a real case will be analyzed, involving the Natura franchises, the Brazilian cosmetics industry. To this end, an online planning and advertising campaign will be prepared for a Natura franchise (physical store), aiming to expand its sales, without entering into ethical and professional competition conflicts with the franchisor itself.
\end{abstract}

Keywords: Entrepreneurial Education. Publicity Campaign. Online Advertising; Franchises. Professional Ethics.

\section{RESUMEN}

Este escrito presenta un breve discurso sobre la importancia de la educación empresarial para que podamos profundizar en el tema central de este escrito, que es la campaña de publicidad en línea. Para ello, se analizará un caso real, que involucra a las franquicias de Natura, la industria cosmética brasileña. Para ello, se preparará una campaña de publicidad online y planificación para una franquicia Natura (tienda física), con el objetivo de ampliar sus ventas, sin entrar en conflictos éticos y profesionales de la competencia con el propio franquiciador.

Palabras clave: Educación Empresarial. Campaña Publicitaria. Publicidad en Línea. Franquicias. Ética Profesional.

\footnotetext{
1 Bacharel em Administração. E-mail: h.muller1997@gmail.com
}

\section{CONMRGÊNDASTEÓRCASDOMNDOCONIEMPORÂNEO}




\title{
INTRODUÇÃO
}

O conceito de educação empreendedora está intrinsecamente relacionado ao ato de educar para lidar bem com o dinheiro. Por essa razão, sua importância se estende a todos os setores de atuação humana, bem como nos mais diversos níveis de educação e ensino, especialmente os formais.

Esse tema é relevante para toda a sociedade, pois discute sobre caminhos que podem levar o homem a se relacionar bem com o dinheiro e usá-lo de forma eficiente e consciente.

Em se tratando de especificamente de empreender, é importante que antes de pôr em prática as habilidades gestoras e de liderança, também é facultativo que se saiba administrar os recursos financeiros que se tenha em mãos, por essa razão, empreender e lidar com o capital são ações que requerem cautela e conscientização de cada passo no processo de gestão.

Gerber (2004) aponta três diferenças entre os personagens relacionados as atuações organizacionais, que são:

\begin{abstract}
O Empreendedor, que transforma a situação mais trivial em uma oportunidade excepcional, é visionário, sonhador; o fogo que alimenta o futuro; vive no futuro, nunca no passado e raramente no presente; nos negócios é o inovador, o grande estrategista, o criador de novos métodos para penetrar nos novos mercados. O Administrador, que é pragmático, vive no passado, almeja ordem, cria esquemas extremamente organizados para tudo. O Técnico, que é o executor, adora consertar coisas, vive no presente, fica satisfeito no controle do fluxo de trabalho e é um individualista determinado. (GERBER, 2004).
\end{abstract}

A Educação Empreendedora, segundo Dolabela (2004, p. 2), (...) se volta para a comunidade, e não apenas para o indivíduo. Mas, trabalha-se o indivíduo em razão, se der ele o foco maior dos benefícios deste processo, pois o empreendedor é o indivíduo que pode propiciar utilidade para outras pessoas, gerando valor para a comunidade e entorno.

Uma Educação Empreendedora, visa através da propagação e do desenvolvimento da cultura do empreendedorismo, a formação de uma sociedade mais capacitada para enfrentar os impasses e as transformações do mundo globalizado e informatizado. Tornando-os, sobretudo, pessoas com plena de consciência de suas responsabilidades e ações ante o desenvolvimento de sua comunidade e, numa esfera político-econômica, dos rumos do país.

\section{CONMRRGÂNAASTEÓRCASDOMNDOCONIEMPORÂNEO}




\section{VISÃO DE MARKETING DO PONTO DE VISTA DA PUBLICIDADE ON-LINE}

A publicidade online serve para ampliar o nome da marca e atingir um maior número de público, o que certamente influencia nas vendas. Porém, esse novo modelo de franquia e loja online da própria franqueadora, estreita as possibilidades de vendas das antigas "consultoras de vendas" que atuavam porta a porta, com o auxílio de um catálogo que, permitia que essas vendedoras mensurassem uma margem de lucro maior, pois elas detinham no privado, o valor a pagar para a Natura, e o lucro que poderiam obter ao acrescentar um determinado preço sob o produto vendido. Diante disso, penso que elas terão que se reinventar para explorar os recursos digitais e lucrar por meio de número de vendas.

\section{COMO UMA LOJA FRANQUEADA PODE FAZER PARA VENDER SEUS PRODUTOS ON-LINE?}

Elas terão liberdade de criar suas páginas e ambientes comerciais online, porém, recorrendo aos recursos de propagandas ofertados pela franqueadora, a fim de assegurar direitos autorais de imagem e textos dos envolvidos e dos produtos ofertados. Além de prezarem pela qualidade desses recursos e objetos de divulgação.

\section{COMO FAZER ESSA DIVULGAÇÃO, CONCORRENDO EVENTUALMENTE COM O E-COMMERCE DA PRÓPRIA NATURA?}

A criatividade será o ponto pacífico deste processo, por isso, esses empreendedores terão que usar da criatividade e a inovação para alavancarem suas vendas e se destacarem frente à concorrência com a própria franqueadora. Pedindo por exemplo, aos clientes que curtam suas páginas, divulguem seus produtos, comentem sobre a experiência na loja...

Além de buscar atrair esse público para o espaço-físico, onde eles têm a possibilidade de fazer promoções, ofertar brindes e explorar em ápice dos recursos táticos, visuais e do atendimento customizado, com um cafezinho e provas dos produtos por exemplo. 


\section{ANÁLISE SWOT (PONTOS FORTES, FRACOS, OPORTUNIDADES E AMEA- ÇAS)}

O mercado de estética e cuidado é um dos que mais cresce no mundo, e isso é impulsionado cada vez mais pela adesão de homens, mulheres e adolescentes. Nesse sentido, iremos aqui pontuar esses nichos e alertas para que 0 empreendimento tenha êxito.

Segundo Porter (1998):

Desenvolver estratégia é desenvolver modos de como uma empresa irá garantir sua competitividade, ressaltando quais serão seus objetivos, quais serão as políticas necessárias para que a empresa consiga atingir seu objetivo (PORTER, 1998).

Em se tratando na Natura, as oportunidades são ainda mais promissoras, haja vista que seu nome está atrelado à qualidade e a responsabilidade social e ambiental, o que impacta na escolha por uma empresa sustentável e bem-vista aos olhos do público.

Figura 1. Matriz SWOT

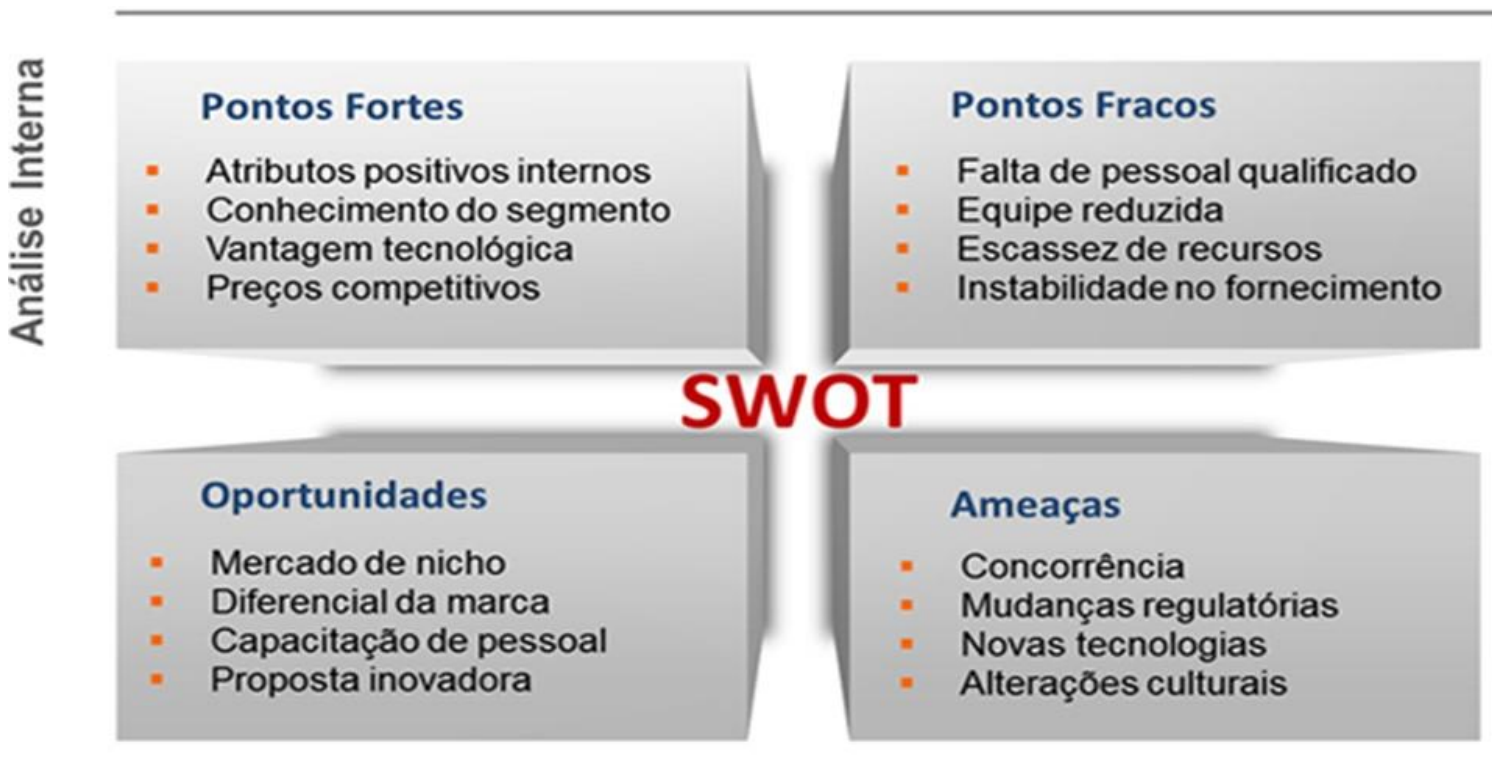

Fonte: Disponível em: https://www.sabrinanunes.com/posts/como-fazer-uma-analise-swot-doseu-negocio/ Acesso em: 24 ago. 2021. 


\section{PONTOS FORTES PARA AS LOJAS FÍSICAS E VIRTUAIS}

\section{- Físico}

Possibilidade de testar a qualidade, fragrância, textura do produto a qualquer momento;

Maior facilidade em fidelizar novos potenciais consumidores;

Maior segurança em realizar a compra e fazer o pagamento na loja física;

Mais possibilidades de "pechincha";

Não depende de conectividade e nem de tempo para cuidar das divulgações online e atualização dos conteúdos;

\section{- Online}

A criação de franquias contribui para a criação de empregos formais e a maior capacitação dos colaboradores;

Atinge um número maior de pessoas;

Zero custo com aluguel, móveis, aparelho...típicos de um espaço adaptado para receber o público.

Baixo custo com divulgações e propagação de propagandas em redes sociais;

Possibilidades de contato com os clientes em momentos em que a loja estaria fechada $(\ldots)$

\section{PONTOS FRACOS PARA AS LOJAS FÍSICAS E VIRTUAIS}

\section{- Físicas}

Estão em desacordo acordo com as necessidades de segurança sanitária e distanciamento social, por conta da pandemia;

Caso a pandemia tenda a se alargar, os sites continuarão funcionando, pois não demandam contato físico, o que altera a rota do cliente;

Não favorece comodidade da compra, tal quais os recursos digitais, onde o cliente tem uma gama de opções de produtos, preços a serem comparados e maior possibilidades de parcelamento;

Implica em locomoção do cliente;

\section{CONMRRGÂNAASTEÓRCASDOMNDOCONIEMPORÂNEO}


Apresentam um custo inicial muito elevado moderado com o passar do tempo, devido aos gastos com água, luz, aluguel do estabelecimento, folha de pagamentos etc.

\section{- Online:}

Não garante 100\% de segurança dos dados pessoas e bancários dos clientes;

Não há possibilidade de provar o produto;

Burocracia nos procedimentos de estornos e trocas;

Inseguranças por não ter um espaço onde o cliente possa ir; (...)

\section{- Oportunidades para ambos os ambientes}

O brasileiro de forma geral é desconfiado, então, a loja física irá sanar eventuais dúvidas sobre a veracidade e qualidade do produto;

Após a pandemia terá um ótimo mercado, uma vez que muitas pessoas optarão por sair de suas casas para realizar;

Aliar o comércio digital com o físico pode potencializar as vendas e divulgação de ambas as lojas e produtos;

O ambiente virtual está em constante crescimento e propiciar muitos recursos e meios para atingir diversos públicos e setores;

\section{- Ameaças}

Aumento de impostos poderá dificultar a manutenção da loja;

O público pode mudar sua postura de compra pós-pandemia e evitar contatos físicos;

Processos trabalhistas por algum deslize no que se cobra do funcionário em relação ao horário de trabalho;

Fraudes por meio de sites falsos;

A concorrência tem mais acesso às investidas/ações da empresa a e pode alterar suas estratégias para vencê-la;

Por encontrar-se em meio digital está mais suscetível a ataques hackers; 


\section{ESTRATÉGIAS PARA ATINGIR OBJETIVOS E VENDER MAIS}

O foco será recorrer a carro de som, cartazes e faixas promocionais na frente da loja, realizar promoções e sorteios de prêmios para indicação, curtidas e compras no site da loja e no físico, brindes para compras acima de um determinado valor, atendimento especializado e diferenciado com dia de beleza gratuito na loja...

QUANDO DEVE COMEÇAR UMA CAMPANHA, COMO DO DIA DAS MÃES, POR EXEMPLO, IMAGINANDO QUE ESTAMOS NO INÍCIO DE ABRIL E A DATA COMEMORATIVA É SEMPRE NO SEGUNDO DOMINGO DE MAIO?

Nossa intenção e iniciar o quanto antes, já em Abril, pois assim, teremos mais tempo para ir divulgando as ações e informando os clientes das promoções que faremos.

\section{POSICIONAMENTO}

A Natura inspira e é base para muitas empresas que querem se destacar no mercado. Com branding forte, passa a imagem de uma empresa sustentável e que valoriza seus colaboradores. Além de atuar em multiplataforma a perfumaria volta seus esforços para o horizonte, almejando sempre progredir no país e no exterior.

\section{ESTRATÉGIA E PÚBLICO-ALVO}

Como é de conhecimento geral, a Natura é uma empresa grande, consolidada e bem aceita no mercado, especialmente dentro do universo feminino, que é o grande enfoque desta marca. Tal qual a Onodera divulgou em seu site: "As mulheres gastam cerca de $30 \%$ do salário mensal com estética e beleza", então, aproveitaremos esse gancho para ofertarmos brindes, workshops e dia de beleza gratuito na loja (maquiagem e dicas de cuidados com pele, unhas e cabelos). Já para o público masculino, criaremos folder com pacotes de tratamentos especiais para eles e brindes como (vale chopes, ingressos para jogos...). Além de um espaço de tratamento estilizado ao mundo MAN (com mesa de sinuca, 
pebolim, canais de tv com programa de atividades esportivas, mini lanchonete com cervejas e petiscos a venda...)

Na região em que a franquia será instalada, pode ser que a vizinhança não tenha o hábito de adquirir os produtos na Natura, mas certamente já ouviram falar da marca, o que assegura uma grande vantagem na confiabilidade desta. Outro fator a se considerar será a análise das lojas concorrentes, para poder ofertar o melhor preço e a melhor experiência, seja no atendimento, no conforto do espaço, na comodidade de pagamento e na mobilidade pelo espaço (loja adaptada para cadeirantes e pessoas especiais).

Usaremos os $\mathrm{R} \$ 500,00$ destinados à publicidade para divulgar por meio de um carro de som a loja física e online, pois por se tratar de um bairro pequeno, através deste recurso será garantido que grande parte dos habitantes da região tomem ciência da loja. Além de ajudar nos custos da elaboração dos folders, cartazes e um animador na porta da loja. No ambiente virtual exploraremos os recursos gratuitos das mídias.

\section{OBJETIVO DA CAMPANHA}

O principal objetivo desta campanha publicitária será divulgar a loja e as vantagens de comprar presencialmente, usando o bordão: "A presença não pode ser virtual, porque o presente poderia?". Para alcançar uma maior quantidade de pessoas, produziremos materiais eletrônicos, no intuito de explorar todo potencial das redes sociais e das mídias digitais, especialmente por meio de JivoChat, Email marketing, Nitronews, Plataformas de vendas online, Wix, Canva, Google Ads, Facebook Ads, Google Analytics, WhatsApp, redes sociais. Também tentaremos devulgar a loja e os produtos de forma mais enfática, através de anúncios pagos nos principais meios de comunicação eletrônica e deverão ser mais veiculados em datas o mais próximo possível do dia das mães, uma vez que o brasileiro tem por característica deixar as compras para "última hora".

Content Trends afirma que: $78,1 \%$ das empresas que documentam sua estratégia se consideram bem-sucedidas. Em empresas que não fazem essa documentação, a porcentagem cai para $25,2 \%$. (CONTENT TRENDS, 2017). 
Tal qual estudado, o KPI vem da sigla em inglês para Key Performance Indicator, ou seja, Indicador-chave de Performance. Que serve de base para mensurar se uma ação ou um conjunto destas está surtindo o efeito esperado e atingindo os objetivos propostos pela organização.

Feitas estas considerações iniciais, é preciso se ater à propaganda em si. Devido ao baixo orçamento, a campanha será limitada ao Instagram, Facebook, e-mail marketing e ao WhatsApp Business.

No Instagram será preciso fazer com que a maior quantidade de pessoas veja os produtos, para tanto, recorremos ao KPI para analisar o tráfego de pessoas no site. Em segundo plano, será preciso observar mais a fundo esses dados, pois a quantidade de visualizações não é sinônimo de aumento de prováveis clientes, para evitar a superavaliação, será importante estar atento aos visitantes recorrentes, e mensurar a quantidade de "likes" nas publicações, tendo claro que cada conta só poderá curtir a publicação uma vez.

Já no WhatsApp Business o enfoque será a efetividade na comunicação eficaz, personalizada e pontual ao cliente. Visando atender as suas dúvidas e desejo no momento em que ele chamar. Um bom KPI primário será a taxa de retorno desses contatos em relação a campanha a ele ofertada, pois sabemos que o cliente tente a ser mais "atingido" por essa mídia que as demais, já que acessa com maior frequência. Além dessa medida, também observaremos a frequência de cada consumidor, além do gasto médio que cada um.

\section{CONSIDERAÇÕES FINAIS}

Neste trabalho foi apresentada uma breve visão acerca da possibilidade de pôr o empreendedorismo em prática especialmente, no âmbito de franquias, explorando os recursos midiáticos e tecnológicos digitais sociais, ancorado em um planejamento de publicidade online bem estruturado, coeso e coerente.

Também se discutiu acerca da educação empreendedora e sua importância para a sociedade, nos mais diversos âmbitos de formação e educação social (formal e informal). Por fim, foi apresentado um modelo de possibilidade de uso da Análise SWOT, visando descobrir e atingir os pontos fortes - fracos, as oportunidades e ameaças de um empreendimento ou negócios. 


\section{REFERÊNCIAS BIBLIOGRÁFICAS}

ARAUJO, O. Análise SWOT (Forças, Fraquezas, Oportunidades e Ameaças). Acesso em 17 de abril, 2021.Disponível em: http://www.dearaujo.ecn.br/cgibin/asp/analiseSwot.asp.

DOLABELA, F. C. Pedagogia Empreendedora. Revista de Negócios, Blumenau, v. 9, n. 2, p. 127-130, abril/junho 2004. Disponível em http://gorila.furb.br/ojs/index.php/rn/article/viewFile/293/280 Acesso em 03/08/2021.

GERBER, M. E. Empreender fazendo a diferença. São Paulo: Fundamento Educacional, 2004.

GRIFFIN, J. Como conquistar e manter o cliente fiel: transforme seus clientes em verdadeiros parceiros. São Paulo: Futura, 1998.

FRANQUIA NATURA. Natura: como ter a sua? Quais os lucros obtidos? Disponível em: https://revendedor.club/franquia-natura-como-funciona/. Acesso em: 28 abr. 2020.

MENEZES, F. Z. Sem alarde, Natura aposta em franquias, alçando consultoras a donas de loja. Gazeta do Povo, Economia, 9 fev. 2018. Disponível em: https://www.gazetadopovo.com.br/economia/livre. Acesso em: 28 abr. 2020.

NATURA inaugura $100^{\underline{a}}$ franquia: negócio é oportunidade para consultora. Natura, Blog, Mais Natura, 4 set. 2018. Disponível em: https://www.natura.com.br/blog/mais-natura/natura-inaugura-100a-franquia-negocio-e-oportunidade-para-consultora. Acesso em: 28 abr. 2020.

ONODERA. Beleza Feminina. Disponível em: https://www.onodera.com.br/blogfranquias/mercado-de-beleza-mulheres-gastam-30-do-salario 28 abr. 2021.

PORTER, M. E. Competição: estratégias competitivas essenciais. 3. ed. Rio de Janeiro: Campus, 1998. 


\section{ANEXOS - UTILIZANDO AS MÍDIAS SOCIAIS}

\section{Anexo I - Instagram}
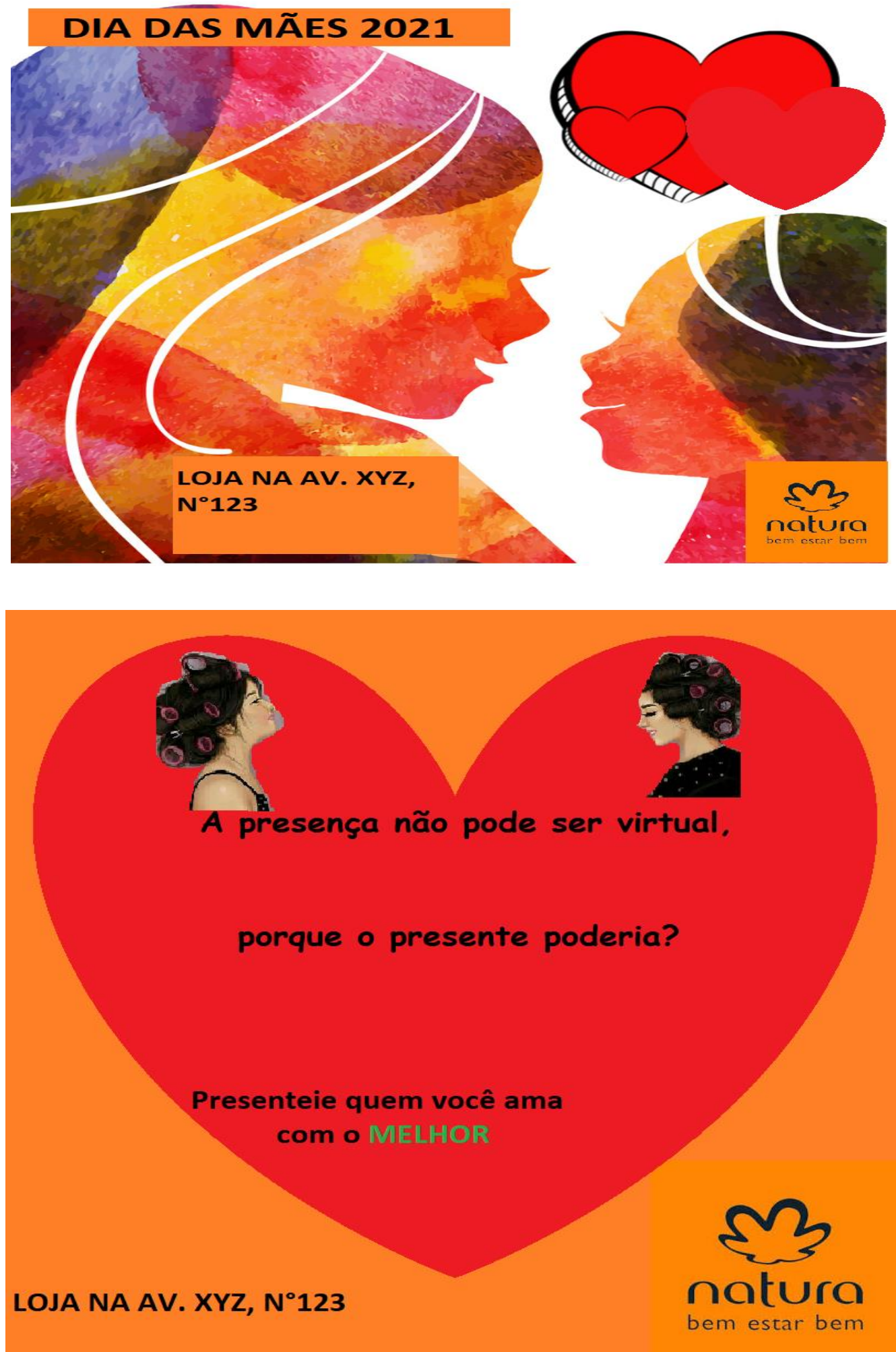

Fonte: Arquivo pessoal.

\section{CONERGÂNAASTEÓRICASDOMNDOCONIEMPORÂNEO}




\section{ANEXO II - WhatsApp Business}

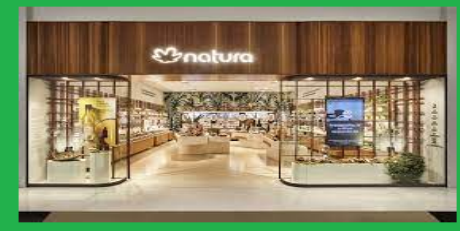

Já conhece nossa loja na Rua XYZ, n¹23???

Ainda não? Então não perca a chance e venha conhecer! Aproveite e leve um presente para aquela mulher tão importante na sua vida!!! Lembre-se: “A presença não pode ser virtual, porque o presente poderia?"

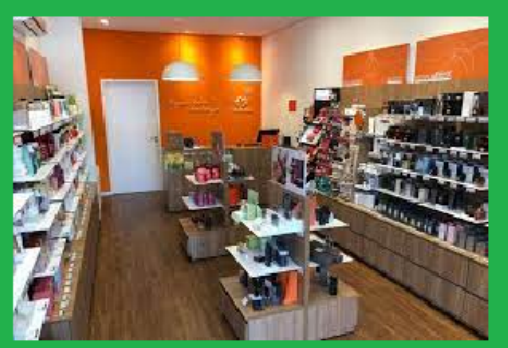

Você já pensou no que vai dar de presente nesse dia das Mães? Ainda não??? Mas ao mesmo tempo ainda pensa... "Ah, não quero dar qualquer coisa, quero algo realmente bom!".

Então seus problemas acabaram! Entre em contato com as nossas consultoras, em nossa loja, e elas certamente irão sugerir um presente inesquecível, assim como sua mãe merece!!!

Enderço: Rua XYZ, $\mathrm{n}^{\circ} 123$

Fonte: Arquivo pessoal.

\section{CONERGÊNDASTEÓRCASDOMNDOCONIEMPORÂNEO}

